\title{
Impact of Frequency of Load Changes in Fatigue Tests on the Temperature of the Modified Polymer
}

\author{
Andrzej Komorek ${ }^{1}$ (D) Z Zenon Komorek ${ }^{2}$. \\ Aneta Krzyzak ${ }^{1}$ - Pawel Przybylek ${ }^{1}$. \\ Robert Szczepaniak ${ }^{1}$
}

Received: 24 June 2016 / Accepted: 23 May 2017 / Published online: 19 June 2017

(C) The Author(s) 2017. This article is an open access publication

\begin{abstract}
In the article, the authors describe the analysis of the impact of the frequency of fatigue tests on the temperature of the modified polymer. The base material for producing the samples was the epoxy resin Epidian 57 cured with $\mathrm{Z} 1$ hardener. The presented study is part of a research program of adhesive joints made with the composition Epidian 57/Z1 aiming to determine the effect of physical modification of the adhesive composition on its properties and on the properties of adhesive joints made with such a modified composition. The tested adhesive compositions were modified by additions of micro- and nanoparticles in an amount of $1.85 \%$ (micro- and nanoparticles) or $10 \%$ (microparticles) in weight, depending on the type of the particles. In the studies, the authors used the particles of tungsten, microspheres and carbon nanotubes. The polymer samples produced by casting were loaded with compressive identical, one-sided loads at two different frequencies of load changes. During the tests, the authors recorded the temperature changes as a function of the number of cycles. The changes in the temperature field on the surface of the samples during the tests were observed by the infrared camera. As a result of the studies, it was possible to observe a significant impact of the composition of the polymer and the frequency of load changes during the test on the temperature of the sample.
\end{abstract}

Keywords Epoxy resin · Fatigue test · Physical modification of polymer · Polymer . Temperature of sample

Selected Papers of the 13th International Symposium on Temperature, Humidity, Moisture and Thermal Measurements in Industry and Science.

\footnotetext{
$凶 \quad$ Andrzej Komorek

komman@op.pl

1 Polish Air Force Academy, Dȩblin, Poland

2 Military University of Technology, Warsaw, Poland
} 


\section{Introduction}

Modern technology of bonding is a novel approach in the field of making long-lasting construction joints. It creates further possibilities in the design, manufacture and repair [1]. Adhesive materials (adhesives, putties, saturants) are widely used in the construction or repair of machinery, vehicles and aircraft [2-5]. In the near future, adhesive bonds may constitute up to $10 \%$ of all joints, due to the numerous advantages of this technology and better properties of structural adhesives.

The use of adhesive structural joints requires knowledge of the properties of both adhesive compositions and the joints which are made using them. The mechanical properties of adhesive compositions, usually polymer materials, significantly affect the strength (especially the cohesive one) of adhesive joints performed by means of them [6-8]. In order to determine the mechanical properties of adhesives, there are usually experimental damage tests conducted, the results of which determine the strength parameters of the examined material [9]. Nowadays to simulate the propagation of delamination in the laminated composite materials subjected to high-cycle fatigue are used analytic methods, as well [10].

The construction application of adhesive materials requires, among others, the knowledge of their durability to variable impact loadings [11]. Bonded structures have high fatigue endurance, if the glue joints are loaded within a limited extent. High fatigue endurance of combined joints, i.e., rivet-bonding and thermal bonding is a well-known fact [12]. However, "pure" adhesive joints are characterized with limited fatigue strength $[13,14]$, which does not indicate a clear correlation with shear strength of such joints. The fatigue endurance of adhesive joints undoubtedly depends upon the properties of the adhesive composite the adhesive joint was made with.

During exploitation, means of transport and construction buildings are often exposed to variable impact loads which may cause sudden destruction of the overloaded structure with loads definitely below their static strength [15]. Additionally, in the case of applying adhesive joints in loaded structures, it is necessary to take into consideration their operating temperature, since their considerable disadvantage is low resistance to temperature changes [16]. In the case of fatigue loads, the variable nature of impact loading can result in a temperature increase in the adhesive joint. This is particularly unfavorable since the temperature change by $20^{\circ} \mathrm{C}$ or $30^{\circ} \mathrm{C}$ may cause significant changes in the properties of the polymer materials, such as adhesives [17-21]. The change in the properties of the hardened joint results in a strength change of the whole bonded structure [22-25].

The investigation, whose findings have been presented in this article, constitute a part of wider research intended to compare the mechanical properties and fatigue life of selected adhesive materials in terms of the possibilities of using these properties to predict fatigue life of adhesive joints. A comprehensive analysis of the available literature indicates that it is difficult to find studies similar to the ones described in this work. This article presents the results of tests which determine the effect of the frequency of fatigue loading changes on the temperature of the polymer material. The basic polymer material designed for testing has been modified physically through the introduction of particles of various materials. The modification was to obtain an 


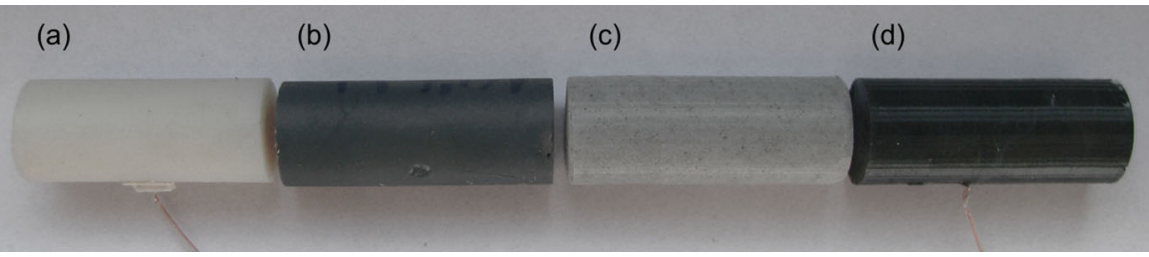

Fig. 1 Test samples of: (a) Epidian 57/Z1 without additives, (b) Epidian 57/Z1 + 10\% T, (c) Epidian 57/Z1 $+10 \% \mathrm{mB}$, Epidian $57 / \mathrm{Z} 1+1.85 \%$ MWCNT

adhesive composition with optimal endurance properties, due to the anticipated load characteristics.

During the test, the temperature of the sample was registered by two methods-by means of a thermoelectric thermometer and a thermal imaging camera.

\section{Materials}

The object of the investigation was the Epidian 57 epoxy resin manufactured by CIECH S.A. Sarzyna, hardened with triethylenetetramine (hardener Z1) and left for 7 days at room temperature of $20^{\circ} \mathrm{C}$. In order to modify the contents of the primary composition, we used 3 different types of particles: tungsten $(\mathrm{T})$ powder of $1.85 \%$ in weight and $10 \%$, ceramic microballoons (microspheres) $(\mathrm{mB})$ of $1.85 \%$ and $10 \%$ in weight and multiwalled carbon nanotubes (MWCNT) of $1.85 \%$ mass share. The examples of the compositions are presented in Fig. 1.

The choice of tungsten powder as a modifier of the bonding composition Epidian 57/Z1 was due to very good strength properties of such an adhesive, obtained in static tests, and due to the expected, good thermal conductivity of the composition. The carbon nanotubes as a modifier have been selected in order to examine the behavior, in the fatigue tests, of the bonding composition modified with nanoparticles, which are also characterized with good thermal conductivity. The microballoons, due to their construction, are characterized with low thermal conductivity, prompting the authors to choose this kind of a microadditive as a modifier for the base polymer.

The tungsten particles were 3-4 $\mu \mathrm{m}$ in size. The microspheres which were used for the manufacture of the modified adhesive composition were made from fly ashes in ZUMiR Kozienice works. These are the sphere 10-800 $\mu \mathrm{m}$ in diameter, gas-filled with mostly $\mathrm{CO}_{2}$ and $\mathrm{NO}_{2}$. The material contains mostly silicon dioxide $\left(\mathrm{SiO}_{2}\right)$, aluminum oxide $\left(\mathrm{AL}_{2} \mathrm{O}_{3}\right)$, magnesium oxide $(\mathrm{MgO})$, iron (III) oxide $\left(\mathrm{Fe}_{2} \mathrm{O}_{3}\right)$, potassium oxide $\left(\mathrm{K}_{2} \mathrm{O}\right)$, calcium oxide $(\mathrm{CaO})$ and trace additives of other metals. Multiwalled carbon nanotubes used in the investigation are $90 \%$ pure. They are $10-30 \mu \mathrm{m}$ in length and $10-30 \mathrm{~nm}$ in the external diameter.

The samples were prepared by the gravity casting method. The compositions with microspheres and tungsten powder were mechanically mixed, and the compositions with the addition of carbon nanotubes were mixed by means of an ultrasonicator [26]. In order to prevent sedimentation, after filling the casts, the inlet hole was glued, and 
for a period of curing (approximately $1 \mathrm{~h}$ ), the mold with samples was rotated. The diameter of the prepared samples equaled $14 \mathrm{~mm}$, whereas the length was $30 \mathrm{~mm}$.

\subsection{The Course of the Investigation and the Test Findings}

For the sake of testing fatigue life, the types of reinforcement particles were selected on the basis of preliminary investigation (described below), during which we determined the basic mechanical properties of Epidian 57/Z1 epoxy resin, modified with these particles. At the time of initial investigation, we examined the impact of additives with different physical properties. For the sake of the investigation, we selected materials (resin compositions of Epidian 57 and reinforcement particles) which ultimately varied in the size of the particles, density, hardness, etc. The samples molded from nonmodified and modified resin with a hardener underwent compression strength testing. The test results enabled to determine the suitability of the examined compositions for making bonded joints for the industry.

During the preliminary tests, the authors examined the modified samples with MWCNT, particles of silicon carbide ( $\mathrm{SiC}$ ), particles of tungsten (T), montmorillonite (MMT) and ceramic microspheres $(\mathrm{mB})$. The results of the experiments enabled to determine the strength parameters of the hardened resins as well as specifying the influence of the mechanical properties of the adhesive.

We assumed $1 \%$ share (in volume) of nanotubes, which corresponds to approximately $1.85 \%$ of the mass share. In order to allow the comparison of strength among materials with different additives, the remainder of the compositions had other reinforcing materials added, which also constituted $1.85 \%$ of the mass share. Moreover, in order to examine the impact of increasing the number of particles upon the strength of the adhesive composition, we also decided on $10 \%$ mass share of all the reinforcement materials.

The samples for compressive testing were made by means of a gravity casting method, using a PVC tube. The diameter of the all tested samples equaled $14 \mathrm{~mm}$, whereas the length was $30 \mathrm{~mm}$. In each test, the number of samples amounted to five.

The static compression strength tests were carried out in the laboratory of the Polish Air Force Academy, on the static test machine, Zwick Roell Z100. The test conditions were in compliance with PN-EN ISO 604:2006. The compression speed was $2 \mathrm{~mm} / \mathrm{min}$. In the tests, we determined the Young's modulus (Fig. 2) and the compressive strength (Fig. 3) of all the tested materials [27].

On the basis of the analysis of the graph (Fig. 2), it is possible to observe that:

- Only the composition containing silicon carbide of $10 \%$ mass share is characterized with an increased value of Young's modulus than the base composition, while all other fillers resulted in a decrease in the value of the modulus even by $50 \%$.

- In most cases, the rise in the contents of the additive caused an increase in Young's modulus.

On the basis of the graph (Fig. 3), it is possible to formulate the following conclusions: 


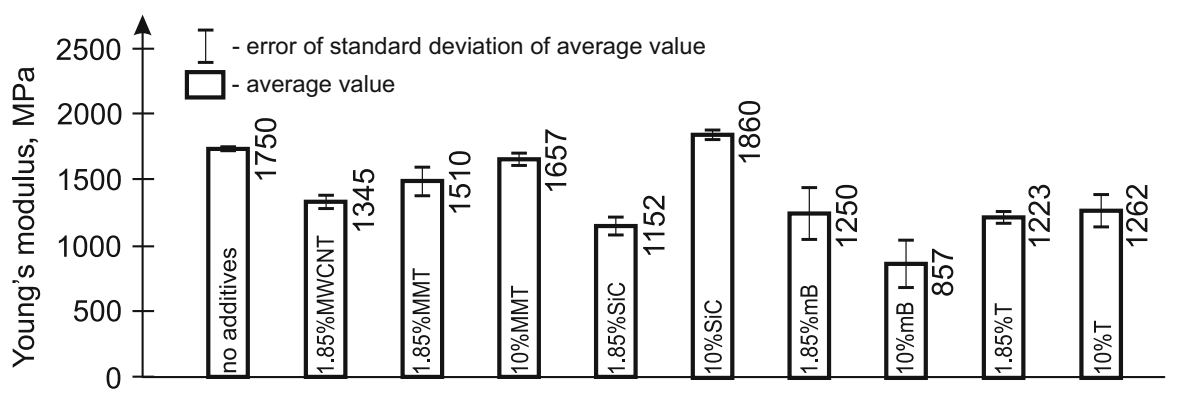

Fig. 2 Young's modulus during compression [27]

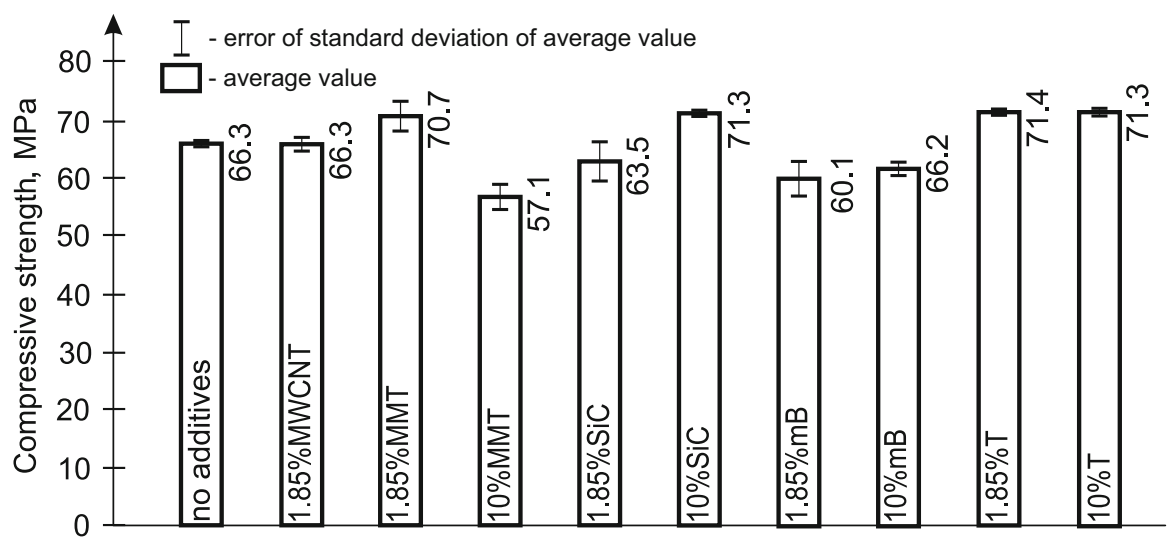

Fig. 3 Compressive strength of the tested materials [27]

- In the four compositions - with the addition of multiwalled carbon nanotubes, silicon carbide $10 \%$, tungsten $1.85 \%$ and tungsten $10 \%$-we obtained very similar results, increased by approximately $7 \%$ than the results for the base composition.

- The largest decrease in the maximum stress (by 14\%) was obtained for the composition with MMT with $10 \%$ mass share.

- For each of the additives that were used, the rise in the amount of a filler caused a slight increase in compressive strength or maintaining the strength on the same level.

Moreover, we conducted testing for all the adhesive compositions in the static tensile strength test. The samples with the addition of tungsten powder and $1.85 \%$ MMT are characterized with the highest tensile strength. (Fig. 4).

\subsection{The Course of the Investigation and the Fatigue Test Findings}

On the basis of the findings presented in paper [28], it was decided to conduct the investigation of a cyclic change of compressive load at the frequency of changing the load amounting to $20 \mathrm{~Hz}$ and $30 \mathrm{~Hz}$. One of the reasons for the selection of such frequencies is an attempt to check the changes of given materials at a typical fre- 


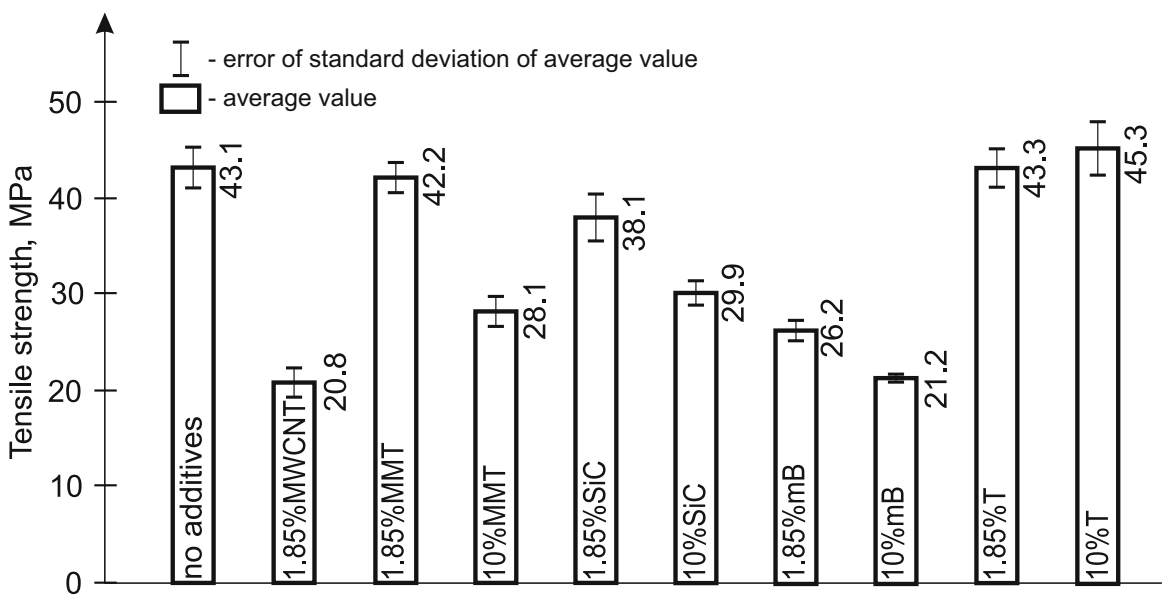

Fig. 4 Tensile strength of the tested materials [27]

quency of flexural and torsional vibrations of an aircraft wing (a typical frequency of $15 \mathrm{~nm} \pm 10 \mathrm{~nm}$ ) during maneuvers for possible applications of adhesive joints in the implementation of field repairs.

The polymer specimens, produced by means of casting, were burdened with identical one-side compressive loads at two frequencies of the impact loading change. The test conditions reflected the actual operating conditions of the adhesive joints (with the specimen set directly at the gripping handles), where the adhesive material is located in-between the metal elements.

During the tests, we recorded changes in the temperature of the material in the function of the number of impact loading cycles. The changes in the temperature field on the surface of the samples during the tests were observed by the thermal imaging camera Flir I60. The local temperature inside the volume of the sample was measured by means of a thermoelectric thermometer with a thermocouple $\mathrm{K}$ or J, whose measurement junction was placed inside the sample, during its preparation (Fig. 5a). Thermocouples in all samples were placed in the same positions (Fig. 5b), what was ensured by the cuts made in the molds in which the samples were cast. Thermal resolution of the thermographic measurement was $0.1{ }^{\circ} \mathrm{C}$ in $25{ }^{\circ} \mathrm{C}$ and accuracy of used camera was $\pm 2 \%$ of measured temperature in whole range of temperature changing. Accuracy of measurement with thermocouple was about $0.6{ }^{\circ} \mathrm{C}$. The impact of the thermocouple on the fatigue properties of testing materials was by authors minimized by placing previously prepared thermocouples in a mold to which the liquid adhesive compositions were casted.

The samples were subjected to identical one-side, sinusoidal compressive loads of the mean value $\mathrm{Fm}=2.8 \mathrm{kN}$ and amplitude $\mathrm{Fa}=1.6 \mathrm{kN}$, at loading frequencies equal to $20 \mathrm{~Hz}$ and $30 \mathrm{~Hz}$. For assumed conditions, the value of maximum load was included with the range of elastic deformation of the base material. All the samples were examined up to $20000 \mathrm{impact}$ load cycles. The temperature with a thermoelectric thermometer was recorded every second, while thermographic images of the samples 

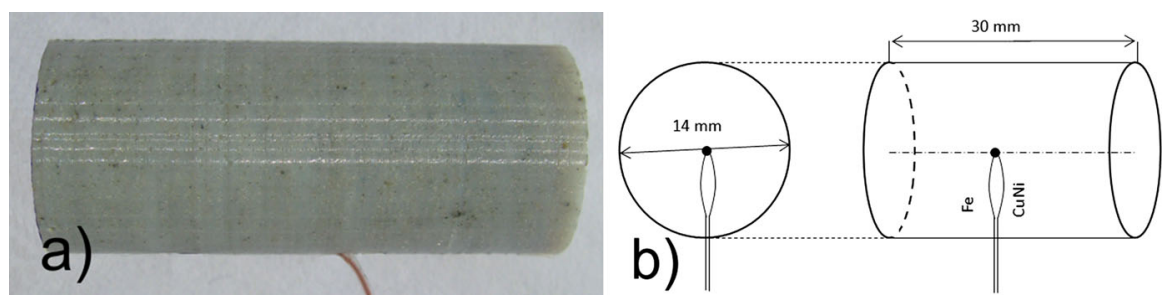

Fig. 5 (a) Test sample made with the composition Epidian 57/Z1 with $10 \%$ addition of ceramic microspheres, (b) placing of thermocouple in the sample

were made every 1000 impact load cycles. The graphs depicted in the figures numbered 6 to 8 , take into account only the temperature measurements made by means of a thermoelectric thermometer.

The test results for the frequency of $20 \mathrm{~Hz}$ have been shown in Fig. 6. Due to the fatigue load, after 14200 cycles, the sample which was $10 \%$ modified with an addition of tungsten powder became damaged, which should not be linked with a temperature increase but rather with the internal fault of the sample. The remaining samples were not destroyed during the test. The lowest temperature rise (approximately $3.5^{\circ} \mathrm{C}$ ) at a frequency of impact load change equal to $20 \mathrm{~Hz}$ was recorded for the composite with a filling in the form of $1.85 \%$ carbon nanotubes, which might indicate that even a small amount of such nanoparticles with good thermal conductivity results in very good heat dissipation to the machine handles that were made of structural steel. The highest increase in temperature (over $5{ }^{\circ} \mathrm{C}$ ) during the testing was observed for the samples made with the modified composite with microspheres. One should note that the increase in temperature was, in principle, independent of the amount of the added microspheres. The rise in temperature in all the samples was nonlinear in its nature. Immediately after the start of the fatigue test, the gradient of temperature increase was the highest and then it was gradually diminishing, except for the modified composite MWCNT, where in the final stage of the test, the gradient of temperature increase was close to the one recorded at the beginning of the test.

The test results for the frequency of $30 \mathrm{~Hz}$ have been shown in Fig. 7. The fatigue test carried out at the frequency of $30 \mathrm{~Hz}$ also resulted in a temperature increase of the examined materials (Fig. 7). None of the samples was damaged during the test. As in the case of research carried out at a frequency of $20 \mathrm{~Hz}$, the highest temperature increase occurred in the material modified with microspheres, with the highest temperature recorded for the modified sample with $1.85 \%$ addition of microspheres $\left(7.4{ }^{\circ} \mathrm{C}\right)$; the temperature grew the fastest soon after the start of the test in case of the material with $10 \%$ share of microspheres. Clearly, the lowest increase in temperature during the test was observed for the material containing $10 \%$ tungsten powder.

We did not measure specific heat of the newly created dispersion composites (in different configurations of the additive); however, once we know approximate values of individual components of the samples, it is possible to estimate specific heat of particular samples, thus:

(a) Samples with the addition of tungsten exercise a significant drop in the value of thermal capacity with a simultaneous rise in thermal diffusivity; in consequence, 


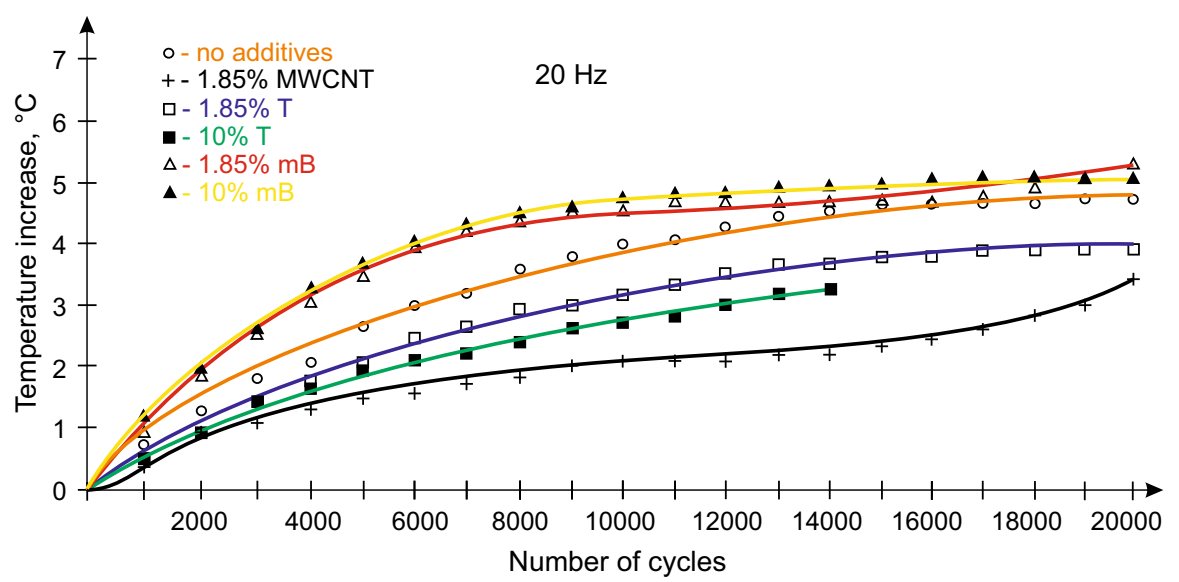

Fig. 6 Impact of the number of cycles upon the temperature of the samples at the frequency of changing the impact load equaling $20 \mathrm{~Hz}$

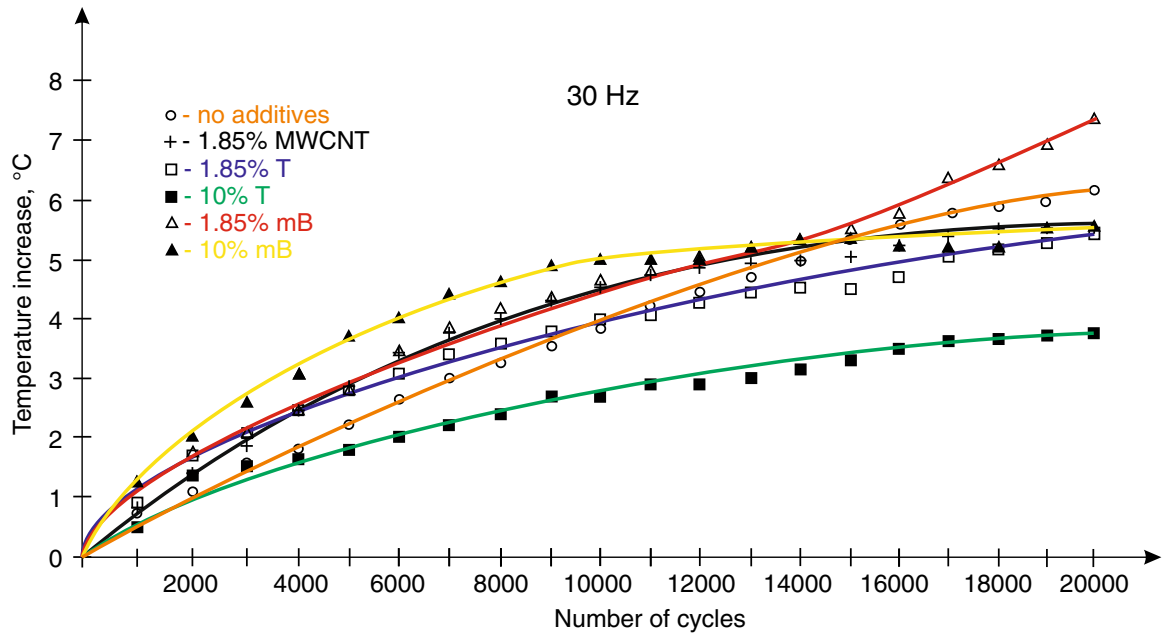

Fig. 7 Impact of the number of cycles upon the temperature of the samples at the frequency of changing the impact load equaling $30 \mathrm{~Hz}$

in the measurements the temperature is given back to the handles much faster (as seen in Fig. 9c), and simultaneously there is a slight flow of heat to the center of the sample, which is depicted in Figs. 6 and 7).

(b) The samples with microparticles as a composite have diminished the specific heat with a simultaneous change in density, as a result of which it is possible to observe a very similar character in a temperature rise in the aspect of its quantity and quality with regard to the base material, which is noticeable in Figs. 6 and 7-higher temperature gradient in the initial stage of the investigation due to a significantly lower density of the samples) 


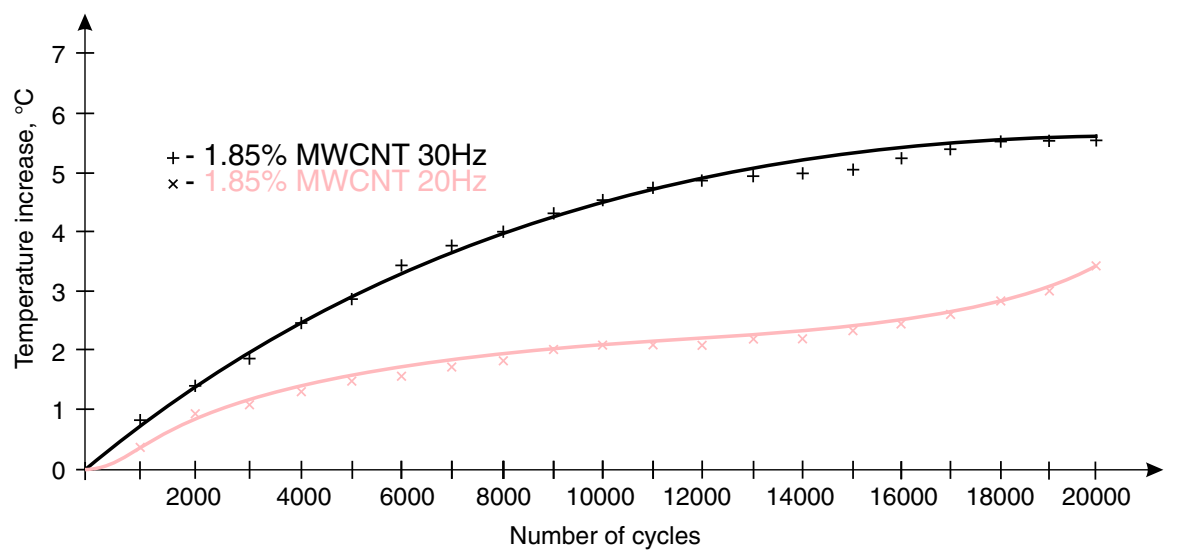

Fig. 8 Effect of the frequency of impact load change and the number of cycles upon the temperature of MWCNT-modified samples in quantities

(c) On the other hand, the sample with carbon nanotubes slightly changed its thermal capacity with a simultaneous increase in the thermal diffusivity coefficient (hence the obtained values in the temperature rise for the frequency of $20 \mathrm{~Hz}$, there is a small growth).

We also compared the results of testing the samples made with the same material and examined at different frequencies of the impact load change. The temperature rise in the composites during the investigation depends upon the frequency of impact load changes, and at a higher frequency, the temperature rise is more rapid. The sample results has been shown in Fig. 8. The character of the curves showing the temperature rise in the composites with the addition of MWCNT during fatigue testing at different frequencies is similar for both samples in the range of 15000 cycles (Fig. 8). After exceeding this number of cycles, at the frequency of $20 \mathrm{~Hz}$, the gradient of a temperature change of the tested composite grows.

The observation of the temperature distribution field of the samples during the fatigue tests enables to obtain more information about the effect of the cyclic load upon the temperature of the sample and points to the area of the highest temperature that can be located in the central part of the sample (Fig. 9d). Apart from the contact of the sample with the steel handles of the testing machine, which receive and conduct heat well, the highest temperature of the sample was often registered at the contact area with the handles of the machine (Fig. 9 a-c). As the investigation indicates, the destruction emerging as a result of fatigue testing always occurs in the area where we observed an increase in the temperature of the material. Further research, which is currently being continued, will enable us to develop a method for assessing the quality of adhesive joints, based on cyclic load tests. The method is to support the anticipation of the behavior of adhesive joints, which is important in designs that take into account the durability of the joint as well as the whole engineering structure. 


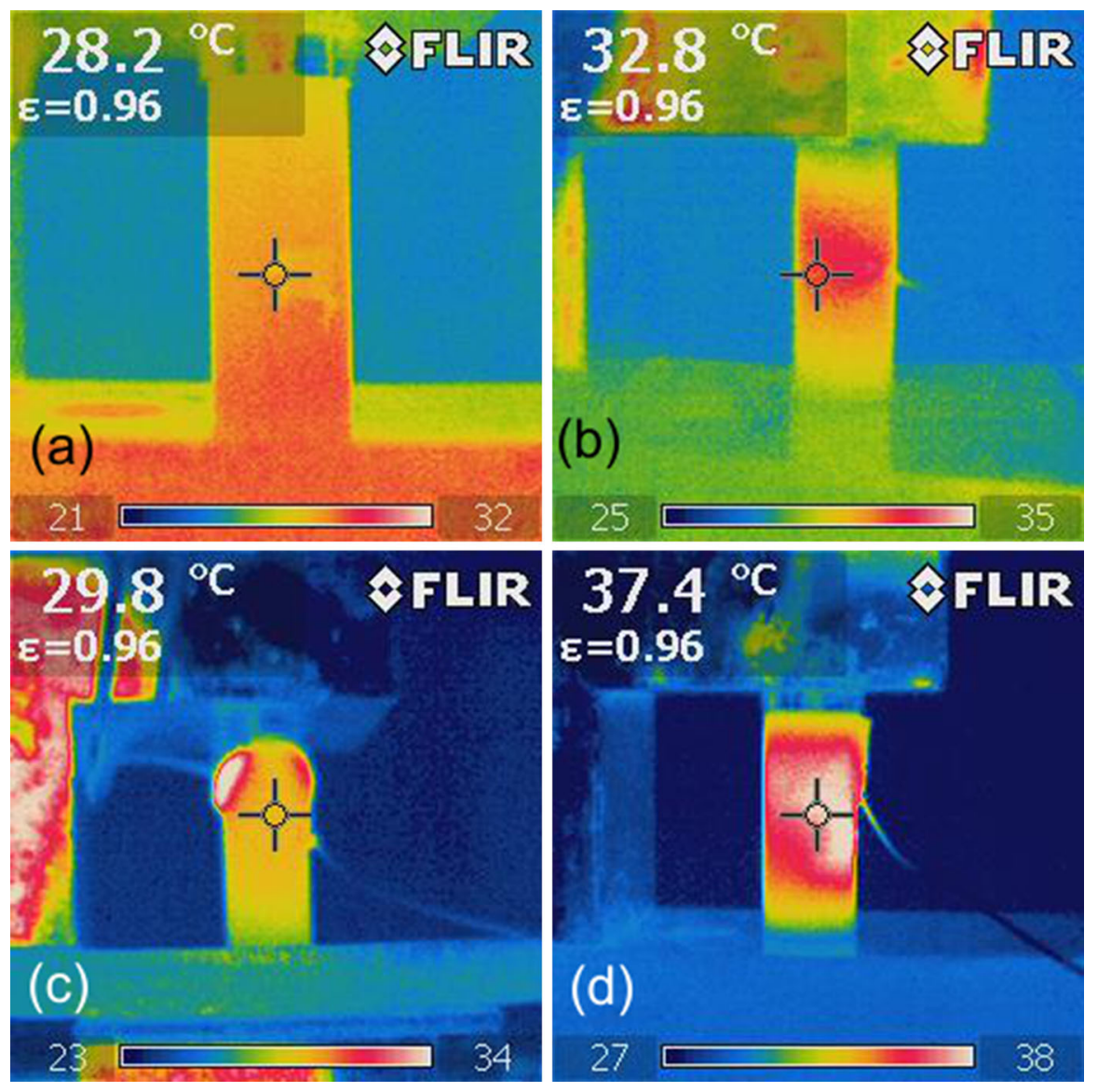

Fig. 9 Examples of thermographic images of samples during the investigation; (a) Epidian 57/Z1 without reinforcement after 9000 cycles $(30 \mathrm{~Hz})$, (b) Epidian 57/Z1 + $10 \%$ T after 10000 cycles $(30 \mathrm{~Hz})$, (c) Epidian $57 / \mathrm{Z} 1+10 \% \mathrm{~T}$ after 14000000 cycles $(20 \mathrm{~Hz})$ immediately before damage which occurred after 14200 cycles, (d) Epidian 57/Z1 + 10\% mB after 8000 cycles $(30 \mathrm{~Hz})$

\section{Conclusions}

1. The addition of tungsten in the amount of $10 \%$ lowers the temperature of the material in relation to pure resin Epidian 57/Z1 in the tests of cyclic compression. In turn, the addition of a reinforcement in the form of ceramic microspheres, to the resin, leads to an increase in the temperature of the samples during fatigue tests.

2. Poor rise in temperature of the adhesive composition with the addition of tungsten is an effect of a good dissipation of the heat by the introduced additive. The addition of ceramic microspheres with a low thermal conductivity results in a higher increase in the temperature of the composition during the dynamic tests. The temperature growth in this case may be also an effect of the friction of the composition with the surface of the spheres. 
3. During fatigue tests of adhesive plastics at a frequency of $20 \mathrm{~Hz}$ and $30 \mathrm{~Hz}$, the temperature of the material shows a rising tendency. The temperature rise is higher with the increased frequency of load changes.

4. In the assumed test cycle (20 000 cycles), the temperature rise should not have a significant influence upon the properties of the examined polymer due to a low value of the absolute temperature change.

5. The results of the temperature measurement obtained with a thermoelectric thermometer are more precise than those obtained using a thermal imaging camera; however, due to the fact that the areas of the highest temperature did not always overlap the location of the thermocouple, the findings of the thermal imaging camera may prove to be more useful.

6. The results of the temperature measurement obtained using a thermometer thermoelectric are more precise than the thermographic ones, as placing the thermocouple inside the sample does not always allow obtaining reliable results due to different areas with the highest temperatures of the sample.

7. If it is necessary to observe the temperature of the adhesive material in a bonded joint, it may be sufficient to use only a thermal imaging camera that allows a detection of areas of the highest temperature which may become potential spots of damaging the joint.

8. In order to determine the actual impact of variable impact loads upon the temperature of the plastic, it is essential to conduct tests where the sample will be isolated from the machine handles.

Open Access This article is distributed under the terms of the Creative Commons Attribution 4.0 International License (http://creativecommons.org/licenses/by/4.0/), which permits unrestricted use, distribution, and reproduction in any medium, provided you give appropriate credit to the original author(s) and the source, provide a link to the Creative Commons license, and indicate if changes were made.

\section{References}

1. F. Tomoyuki, T. Keiichiro, S. Yukinori, Y. Takahiro, S. Yoshinobu, Int. J. Fatigue (2016). doi:10.1016/ j.ijfatigue.2016.02.0230142-1123

2. L.F.M. da Silva, A. Öchsner, R.D. Adams, Handbook of Adhesion Technology (Springer, New York, 2011)

3. A. P. Petrova, N. F. Lukina, Polym. Sci. Ser. D+, 1,2, pp. 83-90 (2008)

4. Y. Ciupack, H. Pasternak, M. Schiel, E. Ince, Steel Construction (2014). doi:10.1002/stco.20141002

5. M. Piekarczyk, R. Grec, Arch Civ. Mech. Eng. (2012). doi:10.2478/v.10169-012-0018-8

6. X. He, in Proceedings of the World Congress on Engineering, vol. II (2010)

7. L.F.M. da Silva, T.N.S.S. Rodrigues, M.A.V. Figueiredo, M.F.S.F. de Moura, J.A.G. Chousal, J. Adhes. (2006). doi:10.1080/00218460600948511

8. D.G. Dixon, W. Unger, M. Naylor, P. Dublineau, C.C. Figgures, Int. J. Adhes. Adhes. 18, (1998)

9. L.F.M. da Silva, D.A. Dillard, B. Blackman, R.D. Adams, Testing Adhesive Joints: Best Practices (Wiley, New York, 2012)

10. Y.V. Skvortsov, S.A. Chernyakin, S.V. Glushkov, S.N. Perov, Appl. Math. Model. (2016). doi:10.1016/ j.apm.2016.03.019

11. J.P. Jeandrau, C. Peyrac, F. Lefebvre, J. Renard, V. Gantchenko, B. Patamaprohm, C. Guinault, Proced. Eng. 133, (2015)

12. M. Imanaka, K. Haraga, T. Nishikawa, J. Adhes. (1995). doi:10.1080/00218469508014356 
13. J. Godzimirski, J. Kozakiewicz, J. Łunarski, W. Zielecki, (O.W. Politechniki Rzeszowskiej, Rzeszów 1997)

14. M.M.A. Wahab, ISRN Mater. Sci. (2012). doi:10.5402/2012/746308

15. X. Zhao, X. Wang, Z. Wu, Z. Zhu, Int. J. Fatigue (2016). doi:10.1016/j.ijfatigue.2016.03.004

16. B.R. da Silva, A.B. Silva Sousa, D.C.R.S. de Oliveira, M.M.M.G. Contente, C.C.A. Román, M.A.C. Sinhoreti, F.C.P.P.de-Souza, Int. J. Adhes. Adhes. 61 (2015)

17. M.D. Banea, L.F.M. da Silva, J. Adhes. 4-5, (2009)

18. M.D. Banea, L.F.M. da Silva, Materwiss Werksttech 5, (2010)

19. H.Y. Hwang, D.G. Lee, J. Adhes. Sci. Technol. 4 (2004)

20. J.H. Lai, C. Knudson, L. Halgreen, R.B. Douglas, P. Griffin, Polym. Eng. Sci. 12 (1981)

21. M. Chanda, S.K. Roy, Industrial Polymers, Specialty Polymers, and Their Applications (CRC Press, Boca Raton, 2008)

22. J. Godzimirski, A. Komorek, Z. Komorek, Biuletyn WAT, LVIII 3, (2009)

23. J. Godzimirski, (WNT, Warszawa, 2010)

24. 1. F. M. Da Silva, R Adams, Int. J. Adhes. Adhes. 27, (2007)

25. S.W. Park, B.C. Kim, D.G. Lee, J. Adhes. Sci. Technol. (2009). doi:10.1163/156856108X344063

26. T.R. Frømyr, F.K. Hansen, T. Olsen, J. Nanotechnol. (2012). doi:10.1155/2012/545930

27. A. Komorek, D. Zmyślony, R. Bieńczak, R. Kowalik, Technika Transportu Szynowego 12, (2015)

28. J. Godzimirski, M. Rośkowicz, A. Komorek, Polimery 10, (2008) 